\title{
COMPARATIVE EVALUATION OF ORALLY DISINTEGRATING FILM OF ONDANSETRON VERSUS INTRAVENOUS GRANISETRON IN PREVENTION OF POSTOPERATIVE NAUSEA AND VOMITING FOLLOWING LAPAROSCOPIC CHOLECYSTECTOMY: A PROSPECTIVE, RANDOMIZED DOUBLE-BLIND PLACEBO-CONTROLLED STUDY
}

Snehalatha Bhashyam¹, P. Krishna Prasad², B. Sowbhagya Lakshmi ${ }^{3}$, Ch. Anny Naveena 4

\section{HOW TO CITE THIS ARTICLE:}

Snehalatha Bhashyam, P. Krishna Prasad, B. Sowbhagya Lakshmi, Ch. Anny Naveena. "Comparative Evaluation of Orally Disintegrating Flim of Ondansetron versus Intravenous Granisetron in Prevention of Post-operative Nausea and Vomiting following Laparoscopic Cholecystectomy: A Prospective, Randomized Double-blind Placebo-controlled study". 2015; Vol. 4, Issue 36, May 04; Page: 6217-6226, DOI: 10.14260/jemds/2015/905

ABSTRACT: BACKGROUND: Ondansetron and granisetron are first generation 5-hydroxytryptamine-3 (5-HT3) receptor antagonists widely used in the prophylaxis of postoperative nausea and vomiting (PONV). Orally Disintegrating Film (ODF) formulations are novel and advanced oral drug delivery systems used in management of (PONV). We aimed to study the efficacy of ODF of Ondansetron in the prophylaxis of PONV and to compare it with intravenous Granisetron and placebo in patients undergoing Laparoscopic cholecystectomy. MATERIALS AND METHODS: In this prospective, randomized double-blind placebo-controlled study, 120 consented adult patients of ASA grade I and grade II, aged between 25-55 years of both genders, undergoing elective Laparoscopic cholecystectomy, were randomized into 3 groups of 40 patients each as Placebo, intravenous Granisetron 2mg and ODF of Ondansetron 8mg (ODF8) groups. Study drugs were administered just before induction of Anaesthesia. Standardized anesthetic technique was used, and data was collected. Incidence of PONV was assessed and the number of patients suffering from nausea and vomiting at 0 6, 7-14, and overall 0-24 hours post-operatively was evaluated in all the groups and need for rescue anti-emetic noted. RESULTS: Data was analysed using one-way ANOVA test, Chi-square test and Mann-Whitney test. The incidence and severity of nausea and vomiting at different time intervals in Group G and ODF Group was significantly lower when compared with Placebo Group ( $\mathrm{p}=0.000)$. But there was no significant difference in between the ODF and intravenous groups. There was no significant difference in the incidence of side effects in between the three groups. CONCLUSION: orally disintegrating film of Ondansetron is a safe, simple and cost-effective, novel formulation, equally effective to intravenous Granisetron in preventing PONV in patients undergoing laparoscopic cholecystectomy.

KEYWORDS: Granisetron, Laparoscopic cholecystectomy, Orally Disintegrating Film, Ondansetron, postoperative nausea and vomiting.

INTRODUCTION: Laparoscopic cholecystectomy has become common and popular elective surgical technique in the management of cholelithiasis now a day's worldwide. But it is often associated with PONV with a high incidence of 70-85\%.1 High rate of PONV in laparoscopy may be due to gas insufflation of the abdomen to create space for the manipulation of instruments. This puts pressure on the vagus nerve, which has a connection to the brain's emetic center. PONV is an unpleasant complication causing more anxiety and discomfort for patients than that caused by post-operative 
pain. 2,3 It causes delayed recovery, prolongs duration of stay in the hospital and increases the cost of treatment in addition to causing inconvenience and poor patient satisfaction. ${ }^{4}$

PONV is multifactorial in etiology. ${ }^{5}$ Different kinds of drugs, regimens, and techniques were evolved from time to time in the prevention and treatment of PONV, antiemetics being the main stay of therapy. The main pharmacological classes of drugs used in the treatment are anti-cholinergics (scopolamine), anti-histaminics (diphenhydramine, cyclizine, promethazine, prochlorperazine), butyropheneones (droperidol), benzamide (metoclopramide), Neurokinin receptor antagonists (NK1 antagonists) and Glucorticoids. Each drug used has its own merits and demerits like dry mouth, extrapyramidal signs, hallucinations, excessive sedation, headache and hypotension. ${ }^{6}$

5-hydroxytryptamine-3 (5-HT3) receptor antagonists are the first-line drugs in the management of PONV with more safety and favourable side effect profile. 5-HT3 antagonists prevent serotonin from binding to 5-HT3 receptors on the nerve endings of the vagus nerve's afferent branches, which send signals directly to the vomiting center in the medulla oblongata and in the chemoreceptor trigger zone (CTZ) of the brain. By preventing activation of these receptors, 5-HT3 antagonists interrupt one of the pathways leading to vomiting. ${ }^{7}$

Ondansetron, is an effective and widely used prophylactic 5-HT3 antagonist, in the prevention and treatment of PONV when compared to traditional antiemetics like droperidol and metoclopramide, with minimal side effects. ${ }^{8}$

Peri-operative prophylactic antiemetics are commonly used parenterally because of the fasting protocols, rapid onset of action, people intolerable to oral intake due to nausea (PONV), pain and sedation.

Orally Disintegrating Films of Ondansetron-ODFs (5-HT3 receptor antagonists) are Novel formulations, a type of oral drug delivery systems proved to be effective in the prevention of chemotherapy and radiotherapy induced nausea and Vomiting approved by The U.S. Food and Drug Administration. Orally Disintegrating Film of Ondansetron is a thin film, which when simply placed on the patient's tongue or mucosal tissue, rapidly disintegrates and dissolves to release the medication for oral mucosal absorption, ${ }^{9,10}$ delivering the drug to the systemic circulation via buccal mucosa, ${ }^{11}$ bypassing hepatic first-pass metabolism resulting in high bioavailability. ${ }^{12}$

Granisetron is highly selective, potent, serotonin 5-hydroxytryptamine type 3 (5-HT3) receptor antagonist which, blocks the 5-HT3 receptors at both the central and the peripheral sites and produces irreversible block of 5-HT3 receptors. It acts on the vagal efferent nerves of the gut and produces blockade of 5-HT3 receptors. It is effective orally as well as intravenous (i.v.), with a halflife of 8-9 h.13

There are only a very few studies which compare the efficacy of Orally Disintegrating Films versus intravenous medications in reducing PONV. So the aim of our study was to compare the efficacy of Orally Disintegrating Films of Ondansetron versus intravenous granisetron in prevention of PONV in patients undergoing laparoscopic cholecystectomy.

MATERIALS \& METHODS: This prospective randomized double blind, placebo controlled study was conducted in Laparoscopic Operation theatre in a tertiary care Government General and Teaching Hospital between October 2014 and March 2015. After obtaining institutional Ethical Committee approval and written, informed consent, 120 adult patients of ASA status Grade I and II, aged between 25-55 years, belonging to both genders were included in the study. 


\section{ORIGINAL ARTICLE}

\section{Exclusion Criteria:}

- Patients with H/o Hypersensitivity.

- Patients on pre-operative antiemetic therapy within 24 hours prior to surgical procedure.

- Patients with Cardiac co-morbidities (QT abnormalities in ECG).

- Morbidly obese Patients.

- Patients with past history of motion sickness.

- Patients with previous history of PONV.

- Pregnant, lactating and menstruating females.

- Patients on opioid and steroid.

The Patients were randomly allocated into 3 groups of 40 each as: Group P - Placebo group, Group G-Granisetron 2mg IV and Group ODF8 - orally disintegrating film of ondansetron 8mg using computer generated random numbers and serially numbered, sealed covers. Before shifting the patients to operating room, the sealed covers were opened and all the patients of 3 groups were administered two ODF's each by one of the observers not involved in intra-operative and postoperative outcome assessments. Patients in the ODF8 group (ODF8) received two ODFs of Ondansetron $4 \mathrm{mg}$ each (Total $8 \mathrm{mg}$ ) whereas patients in the placebo (P) and Granisetron IV (G) groups received two placebo ODF's each.

In the operating room, after connecting all the standard monitoring like heart rate, NIBP, Respiratory Rate, oxygen saturation $\left(\mathrm{SPO}_{2}\right),\left(\mathrm{ETCO}_{2}\right)$ and after securing an intravenous access, all patients were administered study drugs IV just 2 minutes before induction (i.e. $2 \mathrm{mg}$ of Granisetron IV in Granisetron Group (G) and an equal volume of $0.9 \%$ Normal saline in the Placebo (P) and ODF8 Groups each) by the same observer who administered the ODFs and was blinded to outcome assessments.

As per the standard anaesthetic protocol, induction of anesthesia was done by injection propofol $2 \mathrm{mg} . \mathrm{kg}_{-}{ }^{1}$ and inj. Fentanyl $2 \mu \mathrm{g} . \mathrm{kg}^{-}{ }^{1}$. Tracheal intubation was facilitated by inj. vecuronium $0.1 \mathrm{mg} / \mathrm{kg}$ using appropriate sized cuffed ETT. Anaesthesia was maintained using Isoflurane 0.4-0.6\% and $\mathrm{N}_{2} 050 \%$ in $\mathrm{O}_{2}$ to maintain an end tidal $\mathrm{CO}_{2}$ of $30-45 \mathrm{mmHg}$. After intubation a nasogastric tube was passed for suctioning gastric secretions, air and to keep the stomach empty which was removed at the end of the surgery before extubation.

Laparoscopic Cholecystectomy was performed under video guidance and involved four punctures of the abdomen and abdomen insufflated with $\mathrm{CO} 2$ through a veress needle to a maximum intra-abdominal pressure of $15 \mathrm{mmHg}$. During the surgery patients were kept in reverse trendelenburg position with right side of the table elevated. Haemodynamic stability was maintained throughout the procedure.

At the end of surgery, neuromuscular blockade was reversed with injection Neostigmine 50$70 \mu \mathrm{g} / \mathrm{kg} \mathrm{IV}$, inj. Glycopyrrolate $10 \mu \mathrm{g} / \mathrm{kg}$ IV and patients were extubated when adequate spontaneous ventilation was established. Duration of surgery and Anaesthesia were noted. Patients were transferred to Recovery unit. Post-operative analgesia was provided with (NSAIDS) injection diclofenac 50mg intramuscularly, $8^{\text {th }}$ hourly.

Throughout the 24 hours postoperative period, the following parameters were recorded in the Recovery unit and in the ward by an Anaesthesiologist who was not aware of the study protocol and blinded to group allocations. 


\section{ORIGINAL ARTICLE}

- Nausea and Vomiting were assessed in two epochs of 0-6, 7-24 hours.

- Incidence of PONV.

- Overall Nausea and Vomiting over 0-24 hour's period.

- Complete response.

- Rescue antiemetic consumed.

- Incidence of side effects.

Nausea was defined as, unpleasant sensation associated with awareness of the urge to vomit. Severity of nausea was evaluated on a 11-point scale from 0 to 10 where 0 representing no nausea and 10 representing the worst imaginable nausea and the patients of all the groups were graded accordingly.

Vomiting was defined as forceful expulsion of gastric contents from the mouth. PONV was defined as at least one episode of either nausea or vomiting or both during the first 24 hours postoperatively. PONV was graded on a four point (0 to 3) PONV clinical score by Mathew et al.14 and patients with PONV score of 2 or more were given injection Metoclopramide $5 \mathrm{mg}$ IM as rescue antiemetic. Incidence of PONV (the number of episodes of vomiting) and rescue antiemetic consumed by the number of patients for first 24 hours post-operatively were noted in all the groups.

4 - Point PONV Score.

0 - No nausea, no vomiting.

1 - Nausea present, no vomiting.

2 - Nausea \pm , vomiting present.

3 - Vomiting $>2$ episodes in 30 min.

Complete response was defined as no nausea, retching or vomiting, and no need of rescue antiemetic medication within 24 hours in postoperative period. The number of candidates showing complete response was noted in all the groups.

Patients in all the groups were observed for any side effects like headache, dizziness, drowsiness, Allergic reactions and QT interval abnormalities in the ECG and the incidence of side effects were noted.

STATISTICAL ANALYSIS: Statistical analysis was done by using Microsoft Excel and vassarstats.net software. Data were expressed as mean \pm SD or ratio or absolute numbers (\%) and Data was analyzed and compared using one-way ANOVA and Chi-square test to find the significance of study parameters between the three groups of patients. p-value $<0.05$ was considered statistically significant.

RESULTS: 120 adult consented patients were included in the study for their postoperative assessment of PONV. All the patients completed the study successfully. There were no statistically significant differences between the three groups in terms of demographic characteristics of the patients namely age, sex and body weight, ASA physical status, duration of surgery, duration of anaesthesia (shown in Table1).

The incidence of postoperative nausea was significantly lower $(p=0.04)$ during the $0-6 \mathrm{~h}, 7$ $24 \mathrm{~h}$ and 0-24 hours in the Group G and ODF8 groups when compared with the placebo group. The difference in postoperative nausea between the two study groups during the 0-6 $\mathrm{h}, 7-24 \mathrm{~h}$ and 0-24 hours interval was not significant (Table 2). 


\section{ORIGINAL ARTICLE}

During the 0-6 hours interval postoperatively the ODF8 Group had significantly lower incidence of Vomiting when compared to the placebo ( $\mathrm{p}=0.000)$. Also, when compared to the placebo group, IV granisetron (Group G) had a significantly lower $(p=0.045)$ incidence of Vomiting. During the 7-24 $\mathrm{h}$ and 0-24 $\mathrm{h}$ interval, Group G and ODF8 Groups had a significantly lower incidence of Vomiting when compared to placebo group. However there was no significant difference between the study groups in the incidence of Vomiting during the 0-24 hours (Table 2).

The incidence of PONV, as indicated by the PONV Score in the 0-6 hours interval was significantly less $(\mathrm{P}=0.004)$ in the ODF8 Group as compared to the placebo group. There was no significant difference in the PONV Scores between the Study groups in the 0-24 hour's period. The overall incidence of PONV in 0-24 hours period postoperatively was $95 \%$ in the placebo group (Group P), $32.5 \%$ with granisetron (Group G) and 20\% ODF8 Group. The difference between the three groups was considered highly significant with a p value of $(0.000)$ (Table 2$)$.

The number of patients consuming Rescue anti-emetic are 26(65\%) in the Placebo group, $11(27.5 \%)$ in intravenous granisetron group and $8(20 \%)$ in ODF8 Group over the Postoperative period of $0-24$ hours. The difference among the groups was statistically significant $(\mathrm{p}=0.002)$ (Table 2).

The number of candidates showing complete response are two (5\%) in the Placebo group, 27 $(67.5 \%)$ in intravenous granisetron group and 32(80\%) in groupODF8 over the Postoperative period of $0-24$ hours. The difference among the groups was statistically highly significant $(p=0.000)$ (Table 2).

The incidences of side effects were more in patients of placebo group, but with no statistically significant difference in between the groups. None of the patients showed any allergic reactions or Q-T interval abnormalities during the study (Table 3).

DISCUSSION: Laparoscopic surgical procedure was proved to be a major advance in various surgical diseases with several advantages like reduced postoperative pain, better cosmetic results, faster recovery and more rapid return to normal activities, shorter hospital stay, less postoperative wound infection and reduced postoperative pulmonary complications. ${ }^{15}$ PONV is a common and distressing symptom following Laparoscopic surgery. There are various contributing factors that have been identified for the development of PONV.16 These include patient-related factors like increased body weight, female gender, history of motion sickness or previous PONV, perioperative opioid use, nonsmoking status. Surgery-related factors like duration of surgery and anesthesia related risk factors like, use of volatile anesthetics, N20, postoperative opioids, postoperative pain, and intraoperative hypovolemia. ${ }^{17}$ in our study, we have standardized the factors that lead to the development or attenuation of PONV.

Ondansetron and Granisetron are First generation 5-HT3 receptor antagonists used in the prophylaxis of PONV. Orally disintegrating film of ondansetron (ODF) is an advanced formulation containing $4 \mathrm{mg}$ of ondansetron, orally dissolving film available in the Indian Market by Trade name 'Emefilm' (Delvin Formulations PVT Limited, India). It is a pink coloured, strawberry flavoured, thin film which dissolves in few seconds when applied on the tongue. It is well accepted by the patients and its taste being described by most of them as "sweet". This Formulation is particularly useful for patients with dysphagia or anorexia. 


\section{ORIGINAL ARTICLE}

Our study showed that, using orally disintegrating film of ondansetron $8 \mathrm{mg}$ versus intravenous granisetron $2 \mathrm{mg}$ as prophylactic antiemetics before induction of general anesthesia, significantly reduced the incidence of post-operative nausea and vomiting (PONV) in comparison with placebo.

Orally disintegrating film of ondansetron $8 \mathrm{mg}$ was found to be most effective during the 1 st 6 hours post operatively and also as effective as intravenous granisetron $2 \mathrm{mg}$ in preventing PONV during the first 24 hours post-operative period following Laparoscopic cholecystectomy.

The ODF film is easy to administer, no need to take with water unlike oral tablet, better patient compliance, rapid onset of action and as effective as intravenous (IV) preparations, ${ }^{18}$ not associated with pain unlike intravenous injections, no extra expenditure in the form of syringe, needles and biomedical waste. Each film of ODF containing $4 \mathrm{mg}$ of ondansetron is cost-effective which costs about 10 in Indian Rupees whereas a single ampoule of injection granisetron $1 \mathrm{mg}$ costs about 30 in Indian Rupees. However these pricing may be variable. Because of its added advantages we have chosen ODF film of ondansetron as prophylactic antiemetic and compared it with intravenous granisetron in our study.

We restricted use of opioids in our study as they contribute to nausea and vomiting and instead diclofenac 50mg was used for postoperative analgesia. Metoclopramide 5mg IM was used as Rescue anti-emetic.

In their study, Raphael JH, Norton AC.19 stated that the optimal dose of Ondansetron for preventing post-operative nausea and vomiting is $4 \mathrm{mg}$ and half-life is 3 hours. Therefore, in surgical procedures lasting more than 2 hours, it might be more relevant to administer the drug towards the end of the surgery. But as the mean duration of surgical procedure lasted for 1hour in our study we assumed administering the study drugs pre-operatively just before induction was appropriate. The findings of our study correlated with their study, except that, we used $8 \mathrm{mg}$ of Ondansetron in our study instead of $4 \mathrm{mg}$.

Our results are in congruence with the study of Naguib et al. ${ }^{20}$ who demonstrated that the incidence of PONV after laparoscopic surgeries in the placebo group was remarkably high (72\%).

The results of our study correlated with the study of Harihar V Hegde et al. ${ }^{21}$ who compared different doses of orally disintegrating film of ondansetron versus intravenous ondansetron in prophylaxis of postoperative nausea and vomiting in patients undergoing elective gynaecological laparoscopic Procedures. But the difference is, we used intravenous granisetron instead of IV ondansetron in our study and compared it with, orally disintegrating film of ondansetron $8 \mathrm{mg}$ in patients undergoing laparoscopic cholecystectomy.

In a meta-analysis conducted by Tramèr MR. et al. ${ }^{22}$ Ondansetron $8 \mathrm{mg}$ was suggested to be an optimal dose for PONV prophylaxis. In our study also we used ondansetron $8 \mathrm{mg}$ similar to their study.

Ganjare A, Kulkarni AP.23 demonstrated that granisetron 1mg administered before induction of anesthesia was effective for prevention of PONV. The results of our study are in accordance with their study except that, we used $2 \mathrm{mg}$ of granisetron instead of $1 \mathrm{mg}$.

Grover VK. et al. ${ }^{18}$ reported that oral formulations of 5-HT3 receptor antagonists are as effective as intravenous (IV) preparations. The results of our study are in concorde with their study as we also reported that oral formulations of ondensetron are equally effective as intravenous preparations of granisetron in prevention of PONV at the recommended doses. 
In our study, a complete response (no nausea and vomiting) was observed in 32 out of 40 patients (80\%) ODF8 group and in 27 out of 40 patients $(67.5 \%)$ in the intravenous Granisetron group, whereas 2 out of 40 patients ( $5 \%$ ) in the placebo group were free of nausea and vomiting and the difference was statistically highly significant between the placebo and study groups.

The most common side-effects of the drugs in the three groups observed in our study were headache (5\% in group P, $12.5 \%$ in group G and $7.5 \%$ in ODF8 group), drowsiness $(7.5 \%$ in group G and 5\% in ODF8 group) and dizziness (5\% in ODF8 group).The side-effects were of mild nature and self-limiting. There was no significant statistical difference in the side-effects between the three groups.

We did not measure postoperative pain and anxiety which could affect the incidence of PONV and we consider this as a shortcoming of our study.

ACKNOWLEDGMENTS: We are grateful to Dr. B. Sowbhagya Lakshmi, Professor \& HOD Department of Anesthesiology and Critical Care, Ranagaraya Medical College, Govt. General Hospital, KAKINADA, Andhra Pradesh, India for reviewing the manuscript, and we are thankful to local representatives of Delvin Formulations Pvt. Limited, India, for supplying free placebo ODFs for this study.

CONCLUSION: Form our study we conclude that, orally disintegrating film of ondansetron is a novel formulation which is safe, simple and economical with good patient comfort and compliance. It is clinically effective alternative to intravenous Granisetron in preventing PONV in patients undergoing laparoscopic cholecystectomy.

\section{REFERENCES:}

1. Islam S, Jain PN. Postoperative nausea and vomiting (PONV): A review article. Indian J Anaesth 2004; 48: 253-8.

2. Korttila K, Alahuhta S, Ali-Melkkila DT, Tarkkila DP, Hynynen DM. Prevention of postoperative nausea and vomiting-studies on different antiemetics, their combinations and dosing regimens. Biomedicum Helsinki 2003; 26: 1-78.

3. Kreis ME. Postoperative nausea and vomiting. Auton Neurosci 2006; 129: 86-9.

4. Gan TJ, Meyer T, Apfel CC, Chung F, Davis PJ, Eubanks S, et al. Consensus guidelines for managing postoperative nausea and vomiting. Anesth Analg 2003; 97: 62-71.

5. Miller RD. Anesthesia. In: Fleisher LA, Macario A. The postanesthesia care unit. 6th ed. Pennsylvania: Elsevier; 2010. p. 2703-27.

6. Morgan GE, Mikhail MS, Murray MJ. Clinical Anesthesiology.4th edition New York: McGraw-Hill; 2008. Chapter 15, Adjuncts to anesthesia; p.276-88.

7. Hesketh PJ, Gandara DR. Serotonin antagonists: a new class of antiemetic agents. J National Cancer Inst. 1991; 83: 613-20.

8. Helmy SA. Prophylactic antiemetic efficacy of ondansetron in laparoscopic cholecystectomy under total intravenous anaesthesia: A randomised, double-blind comparison with droperidol, metoclopramide and placebo. Anaesthesia. 1999; 54 (3): 266-71.

9. Dixit, R.P. and S.P. Puthli, 2009. Oral strip technology: Overview and future potential, Journal of Controlled Release. 139: 94-107. 


\section{ORIGINAL ARTICLE}

10. Vollmer, U. and P. Galfetti, 2006. Rapid Film: Oral Thin Films as an Innovative Drug Delivery System and Dosage Form. Drug Development Report, pp: 1-5.

11. Mahajan, A., N. Chhabra and G. Agarwal, 2011. Formulation and Characterization of Fast Dissolving Buccal film: A Review; Der Pharmacia Sinica., 3(1): 152-165.

12. Suresh, B., D. Halloran and L. James, 2006. Quick Dissolving Films: A Novel Approach to Drug Delivery. Drug Development Technology. pp: 1-7.

13. Giglio CA, Soares HP, Caparroz C, Castro PC. Granisetron is equivalent to ondansetron for prophylaxis of chemotherapyinduced nausea and vomiting: Results of a meta-analysis of randomized controlled trials. Cancer 2000; 89:2301-8.

14. Mathew PJ, Madan R, Subramaniam R, Bhatia A, Mala CG, Soodan A, et al. Efficacy of low-dose dexamethasone for preventing postoperative nausea and vomiting following strabismus repair in children. Anaesth Intensive Care 2004; 32:372-6.

15. Hunter JG, Trus TL. Laparoscopic cholecystectomy, intraoperative cholangiography, and common bile duct exploration. In: Baker RJ, Fischer JE, eds. Mastery of Surgery, 4th edn. Philadelphia: Lippincott Williams \& Wilkins, 2002: 1152.

16. Leman J. Surgical and patient factors involved in post-operative nausea and vomiting. $\mathrm{Br} \mathrm{J}$ Anaesth 1992; 69 Suppl: 524-32.

17. Gan TJ. Risk factors for postoperative nausea and vomiting. Anesth Analg 2006; 102:1884-98.

18. Grover VK, Mathew PJ, Hegde H. Efficacy of orally disintegrating ondansetron in preventing postoperative nausea and vomiting after laparoscopic cholecystectomy: A randomised, double-blind placebo controlled study. Anaesthesia 2009; 64:595-600.

19. Raphael JH, Norton AC. Antiemetic efficacy of prophylactic Ondansetron in laparoscopic surgery. Randomized double blind comparison with metoclopramide. British Journal of Anaesthesia 1993; 71: 845-48.

20. Naguib M, E I Bakry AK, Khoshi MHB et al. Prophylactic antiemetic therapy with ondansetron, tropisetron, granisetron and metoclopramide in patients undergoing cholecystectomy. Can J Anaesthesia 1996; 43: 226-31.

21. Harihar V Hegde, Vijay G Yaliwal, Rashmi V Annigeri, KS Sunilkumar1, R Rameshkumar, P Raghavendra Rao. Efficacy of orally disintegrating film of ondansetron versus intravenous ondansetron in prophylaxis of postoperative nausea and vomiting in patients undergoing elective gynaecological laparoscopic procedures: A prospective randomised, double-blind placebo-controlled study. Indian J Anaesth 2014; 58(4):423-9.

22. Tramèr MR, Reynolds DJ, Moore RA, McQuay HJ. Efficacy, dose-response, and safety of ondansetron in prevention of postoperative nausea and vomiting: A quantitative systematic review of randomized placebo- controlled trials. Anesthesiology 1997; 87:1277-89.

23. Ganjare A, Kulkarni AP. Comparative electrocardiographic effects of intravenous ondansetron and granisetron in patients undergoing surgery for carcinoma breast: A prospective single-blind randomised trial. Indian J Anaesth 2013; 57:41-5. 


\section{ORIGINAL ARTICLE}

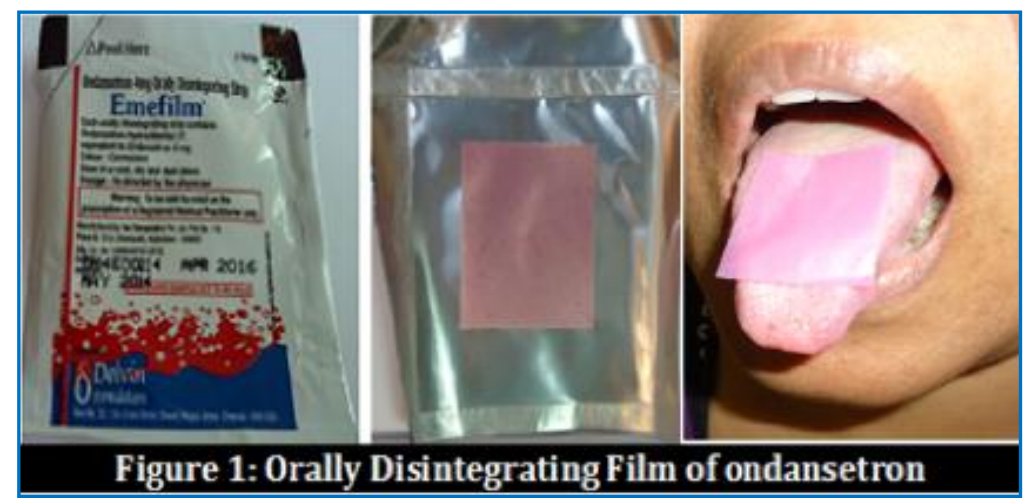

\begin{tabular}{|c|c|c|c|c|}
\hline \multirow{2}{*}{ Parameters } & Group P & Group G & Group ODF8 & \multirow{2}{*}{ P value } \\
\cline { 2 - 4 } & $\begin{array}{c}\text { Mean } \pm \text { SD } \\
\mathbf{n = 4 0}\end{array}$ & $\begin{array}{c}\text { Mean } \mathbf{4} \text { SD } \\
\mathbf{n = 4 0}\end{array}$ & $\begin{array}{c}\text { Mean } \pm \text { SD } \\
\mathbf{n}=\mathbf{4 0}\end{array}$ & \\
\hline Age in years & $36.62 \pm 6.85$ & $37.15 \pm 7.567$ & $36.17 \pm 7.00$ & $\mathrm{p}=0.827$ \\
\hline Bodyweight (Kg) & $55.35 \pm 8.31$ & $54.45 \pm 8.34$ & $54.55 \pm 8.58$ & $\mathrm{p}=0.802$ \\
\hline Sex (Male : Female) & $18: 22$ & $19: 21$ & $17: 23$ & $\mathrm{p}=0.904$ \\
\hline ASA physical status (I/II) & $25: 15$ & $26: 14$ & $28: 12$ & $\mathrm{p}=0.771$ \\
\hline Duration of surgery (Min) & $56.04 \pm 10.24$ & $56.08 \pm 8.02$ & $57.08 \pm 8.38$ & $\mathrm{p}=0.840$ \\
\hline Duration of Anaesthesia (Min) & $63.00 \pm 16.10$ & $64.82 \pm 15.42$ & $65.52 \pm 15.81$ & $\mathrm{p}=0.762$ \\
\hline
\end{tabular}

Table 1: Demographic Data

Data expressed are mean (SD) or ratio or absolute numbers (\%)

*Fischer's exact test

\begin{tabular}{|c|c|c|c|c|}
\hline Time & Group-P $n=40$ & $\begin{array}{c}\text { Group-G } \\
n=40\end{array}$ & $\begin{array}{c}\text { Group-0DF8 } \\
n=40\end{array}$ & $p=$ value \\
\hline \multicolumn{5}{|l|}{ 0-6 Hours } \\
\hline Nausea & $14(35 \%)$ & $4(10 \%)(p=0.018)^{*}$ & $5(12.5 \%)(\mathrm{p}=0.038)^{* *}$ & $\mathrm{p}=0.019$ \\
\hline Vomiting & $12(30 \%)$ & $4(10 \%)(p=0.045)^{*}$ & $0(\mathrm{p}=0.000)^{* *}$ & $p=0.000$ \\
\hline PONV Score 0/1/2/3 & $26 / 2 / 12 / 0$ & $34 / 2 / 2 / 2$ & $35 / 4 / 1 / 0(\mathrm{p}=0.003)^{* *}$ & $\mathrm{p}=0.001$ \\
\hline \multicolumn{5}{|l|}{ 7-24 Hours } \\
\hline Nausea & $12(30 \%)$ & $3(7.5 \%)(p=0.020)^{*}$ & $3(7.5 \%)$ & $\mathrm{p}=0.011$ \\
\hline Vomiting & $9(22.5 \%)$ & $2(5 \%)(p=0.034)^{*}$ & $2(5 \%)$ & $\mathrm{p}=0.023$ \\
\hline PONV Score 0/1/2/3 & $28 / 3 / 9 / 0$ & $35 / 3 / 0 / 2$ & $37 / 1 / 2 / 0(\mathrm{p}=0.003)^{* *}$ & $\mathrm{p}=0.004$ \\
\hline \multicolumn{5}{|l|}{ 0-24 Hours } \\
\hline Nausea & $17(42.5 \%)$ & $7(17.5 \%)(p=0.041)^{*}$ & $6(15 \%)(p=0.021)^{* *}$ & $\mathrm{p}=0.024$ \\
\hline Vomiting & $21(52.5 \%)$ & $6(15 \%)(p=0.003)^{*}$ & $2(5 \%)(p-0.000)^{* *}$ & $\mathrm{p}=0.000$ \\
\hline \multirow{3}{*}{$\begin{array}{l}\text { Overall } \\
\text { Complete response } \\
\text { Rescue anti-emetic }\end{array}$} & $38(95 \%)$ & $13(32.5)$ & $8(20 \%)$ & $\mathrm{p}=0.000$ \\
\hline & $2(5 \%)$ & $27(67.5 \%)$ & $32(80 \%)$ & $\mathrm{p}=0.000$ \\
\hline & $26(65 \%)$ & $11(27.5 \%)(p-0.013) *$ & $8(20 \%)$ & $\mathrm{p}=0.002$ \\
\hline
\end{tabular}




\section{ORIGINAL ARTICLE}

Data expressed as \% and absolute numbers.

Fischer's exact test and, chi-square test,

Comparison of placebo versus granisetron versus ODF8 groups,

** Comparison of placebo versus Group ODF8,

* Comparison of placebo versus Group G.

\begin{tabular}{|c|c|c|c|c|}
\hline Side effects & Headache & Dizziness & drowsiness & Allergic reactions \\
\hline Group P & $2(5 \%)$ & 0 & 0 & 0 \\
\hline Group G & $5(12.5 \%)$ & $3(7.5 \%)$ & 0 & 0 \\
\hline Group ODF8 & $3(7.5 \%)$ & $2(5 \%)$ & $2(5 \%)$ & 0 \\
\hline \multicolumn{5}{|c|}{ Table 3 : Incidence of Side effects in three groups } \\
\hline
\end{tabular}

Data expressed as \% and absolute numbers.

\section{AUTHORS:}

1. Snehalatha Bhashyam

2. P. Krishna Prasad

3. B. Sowbhagya Lakshmi

4. Ch. Anny Naveena

\section{PARTICULARS OF CONTRIBUTORS:}

1. Assistant Professor, Department of Anaesthesiology and Critical Care, Rangaraya Medical College, Government General Hospital, Kakinada.

2. Associate Professor, Department of Anaesthesiology and Critical Care, Rangaraya Medical College, Government General Hospital, Kakinada.

3. Professor and HOD, Department of Anaesthesiology and Critical Care, Rangaraya Medical College, Government General Hospital, Kakinada.

FINANCIAL OR OTHER

COMPETING INTERESTS: None
4. Post Graduate, Department of Anaesthesiology and Critical Care, Rangaraya Medical College, Government General Hospital, Kakinada.

\section{NAME ADDRESS EMAIL ID OF THE CORRESPONDING AUTHOR: \\ Dr. Snehalatha Bhashyam, \\ H. No. 8-11-18/1, \\ Opp. Indian Red Cross Society, Red Cross Street, Gandinagar, \\ Kakinada-533004. \\ E-mail: snehabhashyam@gmail.com}

Date of Submission: 09/04/2015.

Date of Peer Review: 10/04/2015.

Date of Acceptance: 24/04/2015.

Date of Publishing: 01/05/2015. 